Ann. Sci. for., 1983, $40(4), 337-354$

\title{
Possibilités d'appréciation de la sensibilité du genre Larix au Lachnellula willkommii (Hartig) Dennis par inoculations artificielles
}

\author{
Gilberte SYLVESTRE-GUINOT et C. DELATOUR \\ I.N.R.A., Laboratoire de Pathologie forestière \\ Centre de Recherches forestières de Nancy, Champenoux, F 54280 Seichamps
}

\begin{abstract}
Résumé
A l'aide d'unc gamme d'hôtes appropriée, les auteurs ont cherché à déterminer si les différences de sensibilité admises peuvent être appréciées au moyen d'inoculations artificielles. L'objectif est essentiellement méthodologique. La gamme d'hôtes est constituée de 3 espèces : L. decidua, L. eurolepis, L. Leptolepis et pour L. decidua de 3 provenances : Alpes françaises, Sudètes tchèques et Pologne Centrale. Le pathogène est apporté sous forme mycélienne sur blessures artificielles. Les infections sont appréciées suivant plusieurs critères : affaissement de l'écorce (présence/absence), extension latérale, fructifications du champignon, exsudation pathologique de résine, mortalité des organes inoculés.

Le taux final de réussite des infections ne permet généralement pas de distinguer les hôtes entre eux, sauf lorsque les inoculations sont réalisées au mois de décembre. En outre, des différences apparaissent lorsque l'on combine les critères suivants : 1) rapidité d'implantation du pathogène au cours des 3 premiers mois, 2) fréquence des perturbations chancreuses graves (affaissement d'écorce associée à des exsudations pathologiques de résine), 3) importance de l'extension latérale des affaissements d'écorce.

Les classements obtenus indiquent qu'au niveau des espèces $L$. decidua est nettement le plus sensible et qu'au niveau provenance les $L$. decidua des Alpes ont un moins bon comportement que ceux d'Europe de l'Est. La bonne correspondance entre la sensibilité connue en nature et les résultats obtenus par inoculation artificielle montre l'intérêt de l'approche, mais il serait nécessaire de parvenir à distinguer plus finement les hôtes entre eux.
\end{abstract}

\section{Introdıction}

En Europe, une seule espèce de mélèze existe à l'état naturel : le Larix decidua Miller, dont laaire est assez restreinte et morcelée : Alpes, Sudètes, Pologne, Carpates (Fourchy, 1952 ; Pardé, 1957). Les bonnes performances de cette essence ont incité les forestiers à l'étendre hors de son aire naturelle dès le XVII" siècle (FourchY, 1957). Dans l'ouest européen les plantations à basse altitude subissent des pertes importantes dues au chancre provoqué par le Lachnellula willkommii (Hartig) Dennis (HaRtig, 1891: МсСомв, 1955; Gathy, 1959). Cette maladie a donc été un frein très puissant à l'utilisation du mélèze d'Europe comme essence de reboisement (Bouvardel, 1957). 
L'expérience pratique, puis des observations recueillies en Europe dans des plantations comparatives pluristationnelles ont montré qu'il existe de grandes différences de sensibilité entre espèces et provenances. Le mélèze japonais (Larix leptolepis (Sieb et Zucc.) Goud) est souvent considéré comme résistant (Hiley, 1919 ; PlassmanN, 1927 ; Pourtet, 1953 ; Gathy, 1959 ; Kurkela, 1970 ; Schober, 1977), mais au Japon il peut subir des dommages importants (Iто et al., 1963). L'hybride (Larix eurolepis Henry) serait également résistant (EdLIN \& Nimmo, 1956; Schober, 1977). Parmi les nombreuses provenances observées de $L$. decidua, il apparaît d'une façon générale que celles des Alpes sont les plus sensibles (Schober, 1977; PAwsey \& Young, 1969; LEIBUNDGUT et al., 1964) mais à des degrés divers en fonction de leur origine (McComB, 1955). Il semble également que les conditions écologiques ont une grande importance sur le développement de la maladie et l'expression de la résistance, mais dans ces plantations comparatives l'inoculum n'ayant jamais été contrôlé, la connaissance du comportement des différents hôtes demeure imprécise.

Pour un meilleur contrôle de linoculum deux voies d'approche sont possibles : soit la réalisation en nature de véritables tests de sensibilité avec une répartition homogène d'arbres porteurs de fructifications sporulantes, soit la réalisation d'inoculations artificielles. La méthode des inoculations est celle qui permet la meilleure maîtrise de l'inoculum, elle est également d'une réalisation matérielle plus simple.

Dans le passé des inoculations artificielles ont été réalisées par différents auteurs mais, comme nous le verrons plus loin, les résultats obtenus sont difficilement comparables et ne permettent pas de se prononcer définitivement sur l'intérêt de ce type

d'approche. Pour d'autres couples hôte-parasite cependant, il s'est révélé efficace : HAYES (1975) notamment enregistra de grandes différences de comportement au Crumenulopsis sororia Karst \& Groves chez des provenances de Pinus contorta Dougl.

Nous nous sommes donc proposés de déterminer si des inoculations artificielles permettent une bonne appréciation de la sensibilité du mélèze au $L$. willkommii tant au niveau espèces que provenances dans la mesure où les résultats correspondraient à ce qui est déjà connu en conditions naturelles.

\section{Matériel et méthodes}

\subsection{Les hôtes}

\subsection{Les espèces}

Compte tenu des différences de comportement admises selon les espèces, nous avons utilisé la gamme d'hôtes suivante, de sensibilité en principe décroissante : L. decidua (Sudètes et Schlitz), L. eurolepis Henry (Farefolden), L. leptolepis Sieb et Zucc. (Nagano). Il est à souligner que parmi les mélèzes d'Europe les provenances Sudètes sont généralement considérées comme assez résistantes ainsi que Schlitz (provenance artificielle allemande) d'après une expérimentation belge (GALOuX, comm. pers.). Nous n'avons malheureusement pu disposer que d'un petit nombre d'individus issus de semis (respectivement 8, 4, 10) ; ils ont été inoculés successivement en 1978 (âge : 5 ans) et en 1979. 


\subsection{Les provenances}

Trois provenances de $L$. decidua, réputées de sensibilités différentes, ont été employées: Alpes françaises, Pologne centrale, Sudètes tchèques. Il s'agit ici de matériel multiplié par greffage; les trois provenances étaient issues respectivement de 15, 6, 15 individus, en effectif variable et représentant un total de 215 plants qui ont été inoculés 3 ans après le greffage.

\subsection{Organes inoculés}

Les espèces ont été inoculées sur rameaux latéraux âgés de 1 à 2 ans (diamètre $10 \mathrm{~mm}$ environ); et parfois aussi sur les flèches. Les provenances ont été inoculées sur la tige principale, $5 \mathrm{~cm}$ au-dessus de la greffe (diamètre $15-30 \mathrm{~mm}$ ).

\subsection{Le pathogène}

Nous avons effectué toutes les inoculations avec la même souche de $L$. willkommii: isolée à partir de tissus infectés d'un chancre actif de flèche sur $L$. decidua dans les Alpes en août 1976 , puis conservée in vitro à $16^{\circ} \mathrm{C}$ sur bûchettes de mélèze. Pour les inoculations les plus récentes (1979), la souche était fraîchement réisolée (un mois) de rameaux vivants inoculés l'année précédente.

\subsection{L'inoculum}

\subsection{Méthode}

Il a toujours été constitué de mycélium mais sur deux supports différents : soit de la gélose nutritive (gélose au malt 3 p. 100 Difco, pastille de 2 à $4 \mathrm{~mm}$ ), soit des grains d'avoine colonisés (débarrassés de leurs glumellules) incorporés dans de la gélose nutritive.

\subsection{Les blessures}

Toutes les inoculations ont été pratiquées sur blessures réalisées soit par fente longitudinale de l'écorce ( $20 \mathrm{~mm}$ de long) au scalpel, soit par enlèvement d'un disque d'écorce à l'emporte-pièce (diamètre 2 à $4 \mathrm{~mm}$ ). A chaque blessure inoculée nous avons fait correspondre une blessure témoin (qui ne recevait que du support nutritif vierge) situé chez les rameaux à $5-10 \mathrm{~cm}$ de l'inoculation en direction de l'extrémité, chez les tiges $10 \mathrm{~cm}$ au-dessus de l'inoculation.

\subsection{Le mode opératoire}

Les précautions de propreté ont été respectées : nettoyage de l'écorce à l'alcool $70^{\circ}$ puis rinçage à l'eau stérile avant blessure, flambage des outils. Chez les inoculations par fente l'inoculum a été introduit sous l'écorce après avoir légèrement soulevé celle-ci latéralement, chez les autres il a simplement été appliqué sur la blessure. Dans tous les cas un pansement protecteur stérile a été réalisé (coton humide couvert d'une feuille d'aluminium) puis enlevé après un mois (blessures en disque) ou 2 mois (blessures en fente). 
1.34. Les divers essais réalisés

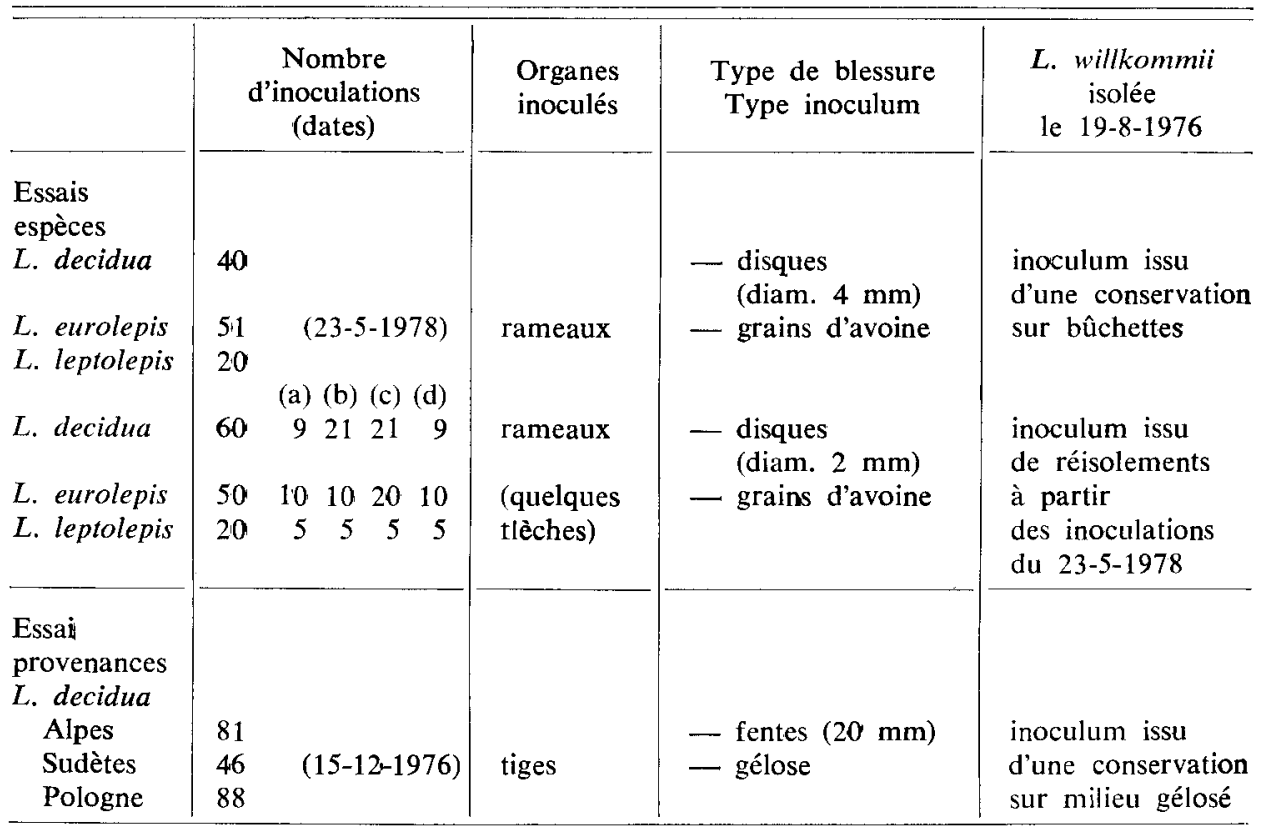
(a) 13-2-1979.
(b) 7-6-1979.
(c) 25-9-1979.
(d) $17-12-1979$.

\section{Résultats}

\subsection{Evolution des symptômes (fig. 1)}

Après les inoculations, les observations ont été effectuées à intervalles réguliers de façon non destructive. Malgré une certaine variabilité des symptômes il est apparu qu'une évolution typique peut être définie par rapport à laquelle tous les cas peuvent être situés. Une bonne connaissance de cette évolution est fondamentale dans la mesure où elle a permis de définir les meilleurs critères d'appréciation de la maladie.

\subsection{Déformations anatomiques}

Dès le troisième mois qui suit linoculation on observe un affaissement des tissus autour de la blessure (bl); verdâtre à l'origine, l'écorce se teinte de jaune et rose-saumon. A la périphérie (L 1) de l'affaissement, les tissus tendent à gonfler au cours du temps par formation de tissus réactionnels qui soulèvent la bordure de l'écorce morte lui donnant l'aspect d'un opercule concave ( $\left.L^{\prime} 1\right)$. L'année suivante l'affaissement de l'écorce reprend au-delà de cette zone de réaction conduisant au développement d'une deuxième ride de 

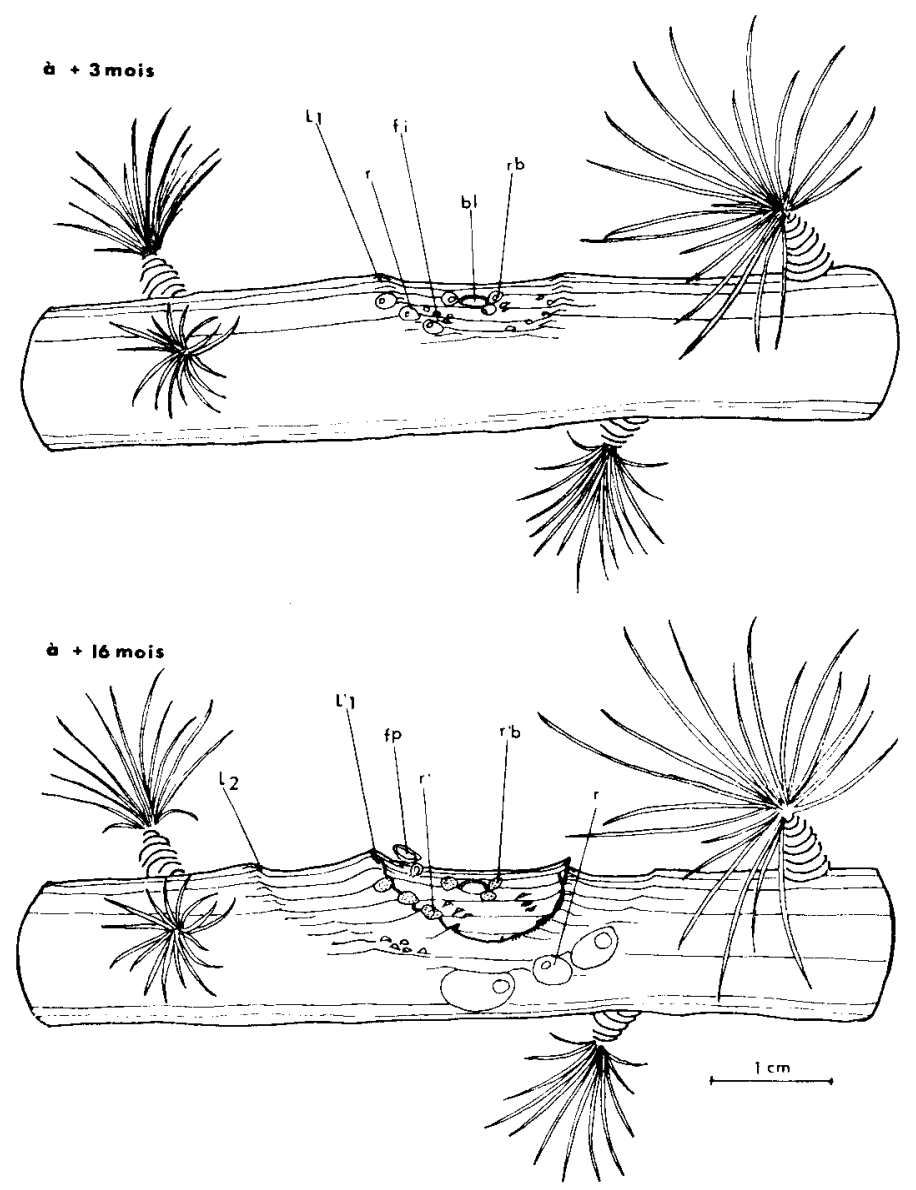

Fig. 1

Evolution des symptômes après inoculation sur blessure à l'emporte-pièce d'un rameau de mélèze par $\mathrm{L}$. willkommii.

$\mathrm{rb}$ : résine blessure.

$r^{\prime} b$ : résine blessure sèche.

$\mathrm{r}$ : résine pathologique.

$r^{\prime}$ : résine pathologique sèche.

fi : forme imparfaite (amas de microconidies).

fp : forme parfaite (apothécies).

b1 : blessure d'inoculation.

L1 : limite de la zone affaissée la $1^{\text {re }}$ année $(3$ mois).

L2 : limite de la zone affaissée à 16 mois.

Development of symptoms after inoculation of a circular wound (made with a cork borer) on a Larch twig by L. willkommii.

$r b$ : wound resin.

$r b$ : dried wound resin.

$r$ : pathological resin.

$r^{\prime}$ : dried pathological resin.

fi : imperfect fruit bodies.

fp : apothecia.

b1 : artificial wound.

L1 : boundary of the bark sunk during the first year.

L2 : boundary of the bark sunk during the second year. 
réaction concentrique à la première (L 2). La vitesse d'extension est variable : jusqu'à dix fois la Iongueur de la blessure en un an; l'extension latérale conduit à la mort de la partie distale du rameau par ceinturation mais en général le processus demeure assez lent. Les rameaux courts au voisinage de la zone perturbée sont affectés, certains dépérissent puis meurent avant même que l'affaissement de l'écorce ne les atteigne.

\subsection{Exsudation de résine}

Les blessures exsudent de la résine ( $\mathrm{rb}, \mathrm{r}$ 'b), mais chez les témoins, l'écoulement ne se poursuit pas après la cicatrisation qui intervient au cours de la première saison de végétation.

Chez les blessures inoculées, par contre, l'écoulement est persistant (r) notamment au voisinage de la ride de réaction. Cette résine colmate parfois complètement la zone malade empêchant toute observation détaillée. Nous avons noté par ailleurs que les exsudations pathologiques sont beaucoup plus fréquentes au début de la saison de végétation (mai-juin).

\subsection{Fructifications du champignon}

Dès que l'écorce s'affaise, la forme imparfaite (fi) peut se développer çà et là à sa surface sous forme de petits amas blancs (microconidies agglomérées), jusqu'à la limite des tissus sains.

Les apothécies (fp) n'apparaissent au plus tôt que l'année suivante à la surface des tissus les plus anciennement touchés.

Ces fructifications semblent pouvoir persister ou apparaître tout au long de l'année ; elles sont cependant moins fréquentes en hiver. Leur disparition est souvent due à l'intervention de prédateurs.

\subsection{Quels critères prendre en compte?}

L'observation des symptômes nous conduit à retenir trois critères pour caractériser l'infection : 1. l'affaissement de l'écorce, 2. l'exsudation pathologique de résine, 3. l'apparition des fructifications.

Ces trois critères manquent totalement chez les blessures témoins; chez les blessures inoculées certains peuvent faire défaut, nous avons considéré que la présence de l'un d'entre eux au moins est nécessaire pour conclure à la réussite de l'inoculation.

Le seul critère quantifiable est l'affaissement de l'écorce. En fait seules les différences d'extension transversales se sont révélées exploitables; cette extension a été estimée par fraction de circonférence d'organe nécrosé $(1 / 4,1 / 2,3 / 4,4 / 4)$.

\subsection{Comparaison des inoculations selon les espèces}

\subsection{Taux d'infection}

Chez les blessures témoins, il est nul dans tous les cas; les résultats obtenus chez les blessures inoculées sont résumés dans les graphiques de la figure 2. 

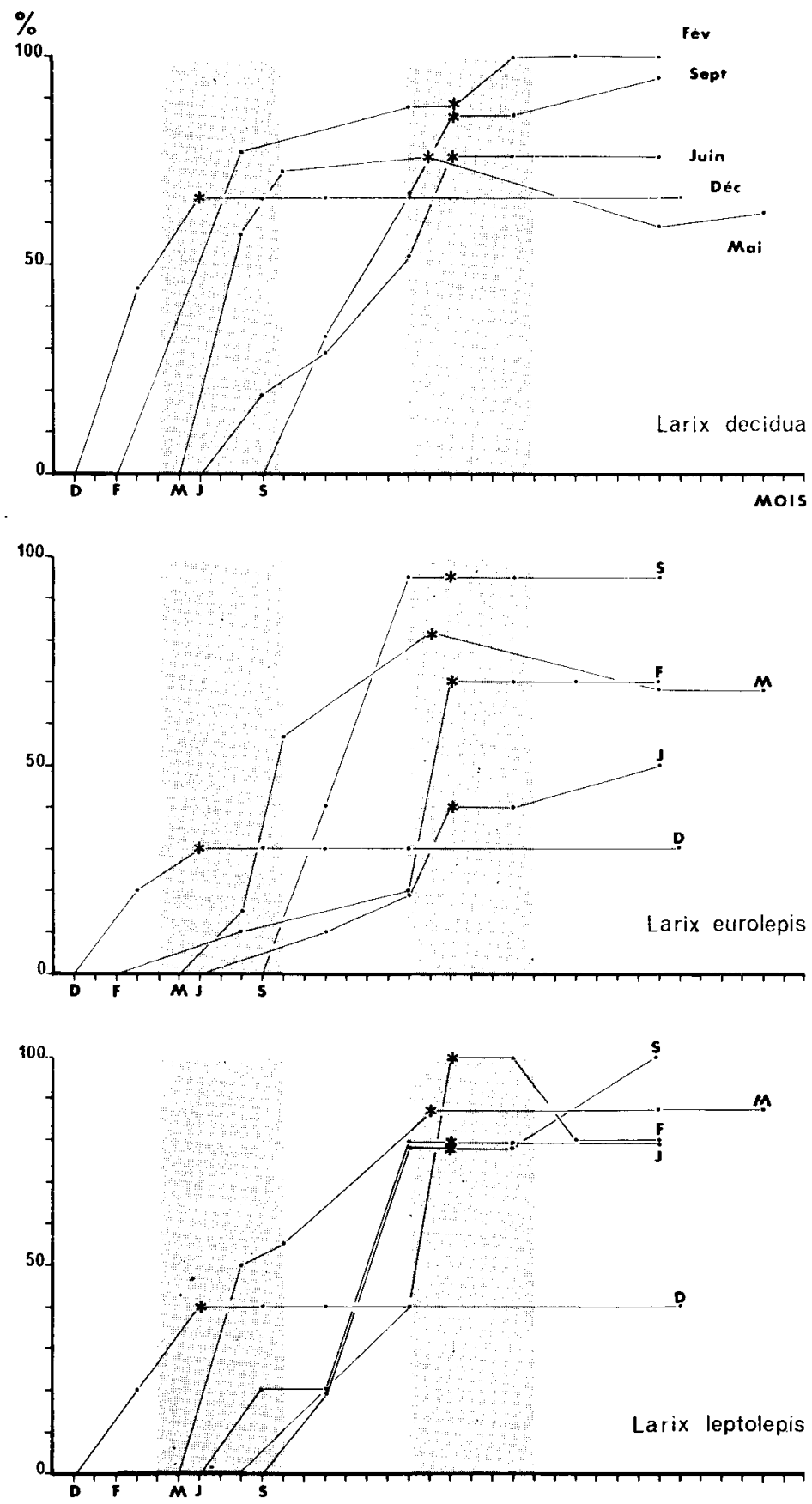

FIG. 2

Evolution du taux d'infection des trois espèces de mélèze inoculées à différentes périodes de l'année.

En grisé : les périodes de végétation.

* : infections réussies analysées dans la figure 4.

Infection rate in the three Larch species inoculated at different times of the year. Greyish areas : vegetative periods.

* : successfull infections analysed in fig. 4. 
Dans les premiers mois qui suivent les inoculations, il apparaît que la rapidité d'établissement des infections est nettement plus élevée chez $L$. decidua que chez les autres espèces.

Le test des écarts réduits montre que, toutes saisons d'inoculations confondues, après 3 mois d'évolution seuls $L$. decidua et $L$. leptolepis sont significativement différents $(\varepsilon=3,47)$. Après 6 mois d'évolution aucune différence significative ne subsiste. Les taux définitifs d'infection (mesurés après 18 mois ou plus) sont élevés et non significativement différents entre espèces, plus variables cependant chez L. eurolepis.

La saison à laquelle sont pratiquées les inoculations exerce une influence non négligeable sur la réussite des infections.

- Celles de décembre permettent un établissement rapide du pathogène. Celui-ci est cependant contrarié au cours de la première saison de végétation et aucune infection nouvelle ne se développe par la suite. Ceci aboutit à des taux d'infection définitifs presque toujours inférieurs à ceux des autres modalités.

- Les inoculations de septembre sont comparables : ici aussi, le taux d'infection cesse d'évoluer (à quelques exceptions près) au cours de la première saison complète de végétation, mais la longue période de repos végétatif consécutive aux inoculations conduit à des taux définitifs de réussite beaucoup plus élevés (90 à 100 p. 100).

La situation des autres inoculations apparaît moins claire.

- Celles réalisées en février ne cessent d'évoluer qu'au cours de la deuxième saison de végétation mais ici l'implantation est très lente voire nulle dans les premiers mois chez $L$. eurolepis et $L$. leptolepis puis très forte au début de la deuxième saison de végétation.

- Parmi les inoculations faites en début de saison de végétation (mai-juin), celles de mai permettent dans tous les cas une implantation plus rapide mais dans ce cas particulier les blessures étaient plus grandes ( $4 \mathrm{~mm}$ au lieu de $2 \mathrm{~mm}$ ).

On peut dire en résumé que comme la rapidité d'implantation du L. willkommii varie suivant la saison d'inoculation, le taux définitif d'infection n'est mesurable qu'à partir de la première période complète de végétation sauf pour les inoculations réalisées en février (seconde saison de végétation).

\subsection{Evolution des infections réussies}

\subsection{Extension latérale au cours du temps}

Nous avons exprimé l'extension latérale de l'affaissement de l'écorce en pourcentage de la circonférence de l'organe concerné. Les résultats sont présentés dans la figure 3 .

Il apparaît ici que l'extension latérale est généralement forte au cours des trois premiers mois et qu'ensuite elle est nettement moins rapide; plus importante cependant chez $L$. decidua et $L$. leptolepis (moyenne 70-74 p. 100) que chez L. eurolepis (moyenne 65 p. 100) chez lequel une stabilisation plus précoce semble avoir lieu. 



FIG. 3

Extension latérale des infections chez les 3 espèces de mélèze inoculées à différentes périodes de l'année.

En grisé : les périodes de végétation.

Lateral extension of infections for the three species of Larix inoculated at different times of the year.

Greyish areas : vegetative periods. 
Le test $\mathrm{t}$ nous indique cependant que la plus grande différence observée, entre L. leptolepis et L. eurolepis, demeure non significative $(t=\mathrm{I}, 76 \mathrm{ddl} 47$; signification citre 5 et 10 p. 100).

Aucune influence saisonnière notable n'apparaît ici.

\subsection{Caractéristiques des infections réussies}

Nous avons distingué plusieurs catégories d'infections selon que laffaissement de l'écorce était accompagné ou non de résine ou de fructifications. Pour chaque espèce nous avons groupé les observations réalisées au début de la première période complète de végétation (mai-juin), toutes saisons d'inoculation confondues (sauf février : deuxième saison de végétation; fig. 4).

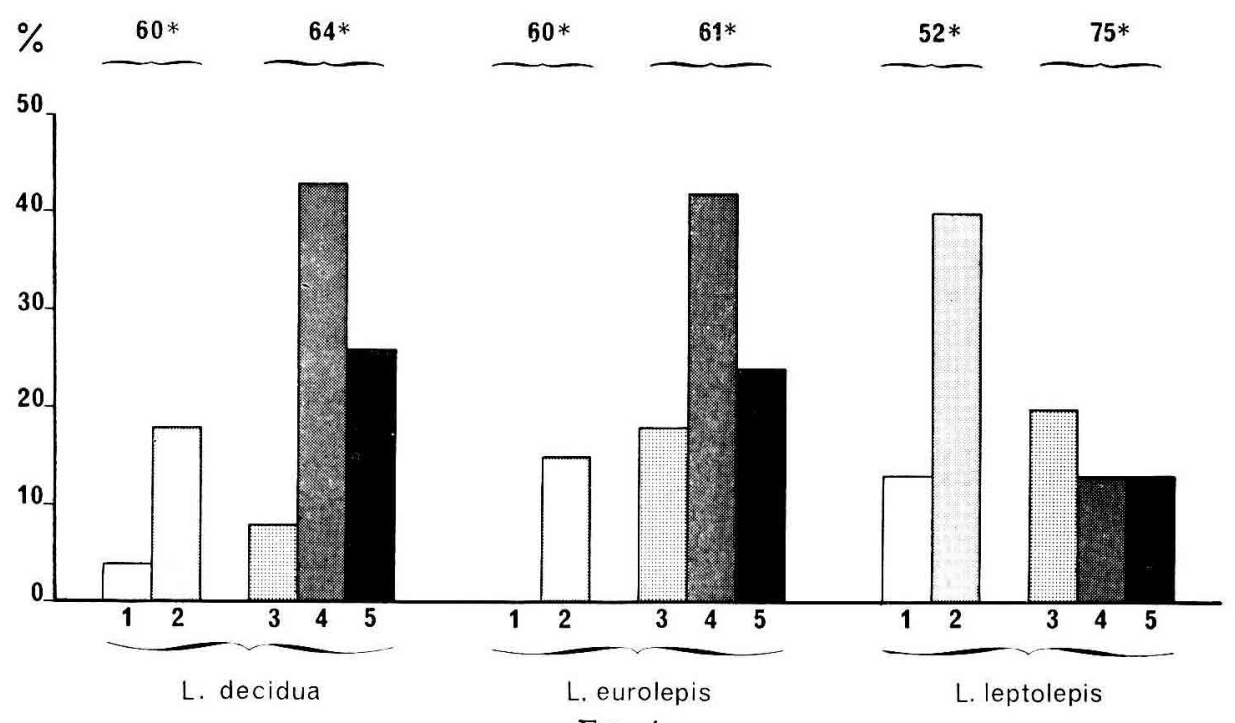

FIG. 4

Caractéristiques des infections réussies chez les 3 espèces de mélèze.

Les infections sont celles qui ont été jugées réussies au début de la première saison complète de végétation (sauf pour février : astérisque de la figure 2); elles sont rangées dans 5 classes définies comme suit :

Symboles 1 : affaissement écorce seule.

2 : affaissement et fructifications.

3 : affaissement et résine.

4 : affaissement, résine et fructifications.

5 : organe inoculé mort à la suite de l'infection.

* : taux d'extension latérale.

Features of the successfull infections in the three Larix species.

The infections are those which were considered successfull at the begining of the first whole vegetative period (except for February : asterisk in fig. 2); they are assessed in 5 classes as follows :

1 : sunken bark only.

2 : sunken bark and fruit bodies.

3 : sunken bark and resin.

4 : sunken bark, resin and fruit bodies.

5 : death of the inoculated twig.

* : lateral extension rate. 
Il apparaît ici que $L$. decidua et $L$. eurolepis se comportent de façon comparable mais différente de L. leptolepis. C'est ainsi que chez ce dernier la réalisation de « chancres complets $\gg$ (classe 4) est beaucoup moins fréquente ( 13 p. 100 contre $42-43$ p. 100), et la mortalité des rameaux également (classe 5).

De fait, la répartition des classes chez $L$. leptolepis est différente au seuil 2 p. 100 de celle de $L$. eurolepis $\left(\chi^{2}=\mathrm{II}, 30\right.$, ddl $\left.=4\right)$ et à un seuil proche de 5 p. 100 de celle de $L$. decidua $\left(\chi^{2}=8,96, \mathrm{ddl}=4\right)$. $L$. decidua et $L$. eurolepis ne peuvent pas être démontrés différents $\left(\chi^{2}=3,50\right.$; ddl $\left.=4\right)$.

On remarque également que l'extension latérale est la même quelles que soient les caractéristiques des infections chez $L$. decidua et $L$. eurolepis alors que chez $L$. leptolepis les extensions fortes ne sont le fait que des évolutions chancreuses typiques.

\subsection{Comparaison des inoculations selon les provenances (L. decidua)}

\subsection{Taux d'infection}

Les résultats sont consignés clans la figure 5. Les taux d'infection notés au bout de huit mois sont ici peu fiables car l'écoulement pathologique de résine ne peut pas être pris en compte; les témoins, en effet, présentent encore des écoulements importants (ceci est lié à la dimension des b!essures).
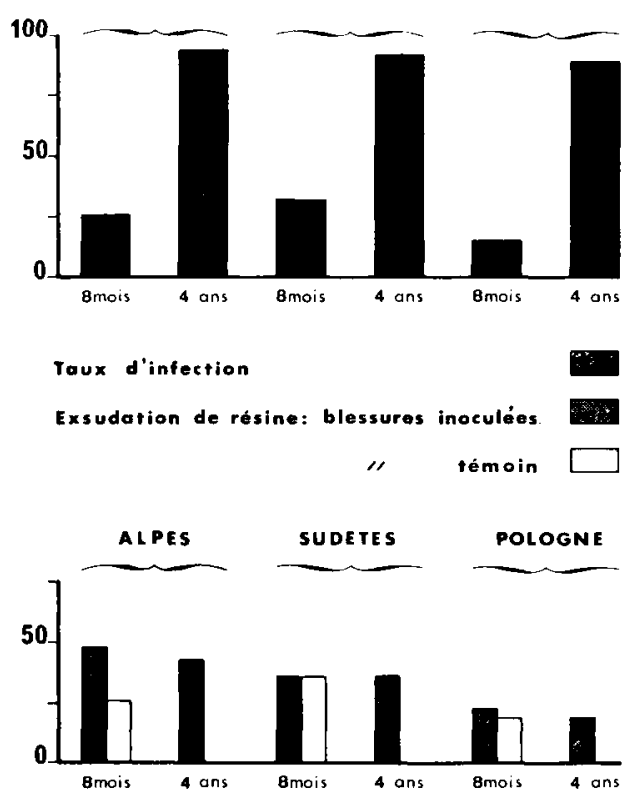

FIG. 5

Evolution du taux d'infection et de l'écoulement de résine chez trois provenances de Larix decidua inoculées en décembre.

Infection rate and resin exudation of $\mathrm{L}$. decidua from three provenances, inoculated in December. 
$\mathrm{Au}$ bout de quatre ans, les taux d'infection définitifs sont élevés et diffèrent peu entre eux.

En fait, seule l'exsudation globale de résine permet une certaine distinction des provenances, aussi bien après huit mois (résine de blessure + résine pathologique) qu'après quatre ans (résine pathologique seule).

\subsection{Evolution des infections réussies}

\subsection{Extension latérale}

Elle n'a été notée ici que quatre ans après l'inoculation. La figure 6 montre qu'elle est plus importante pour la provenance des Alpes.

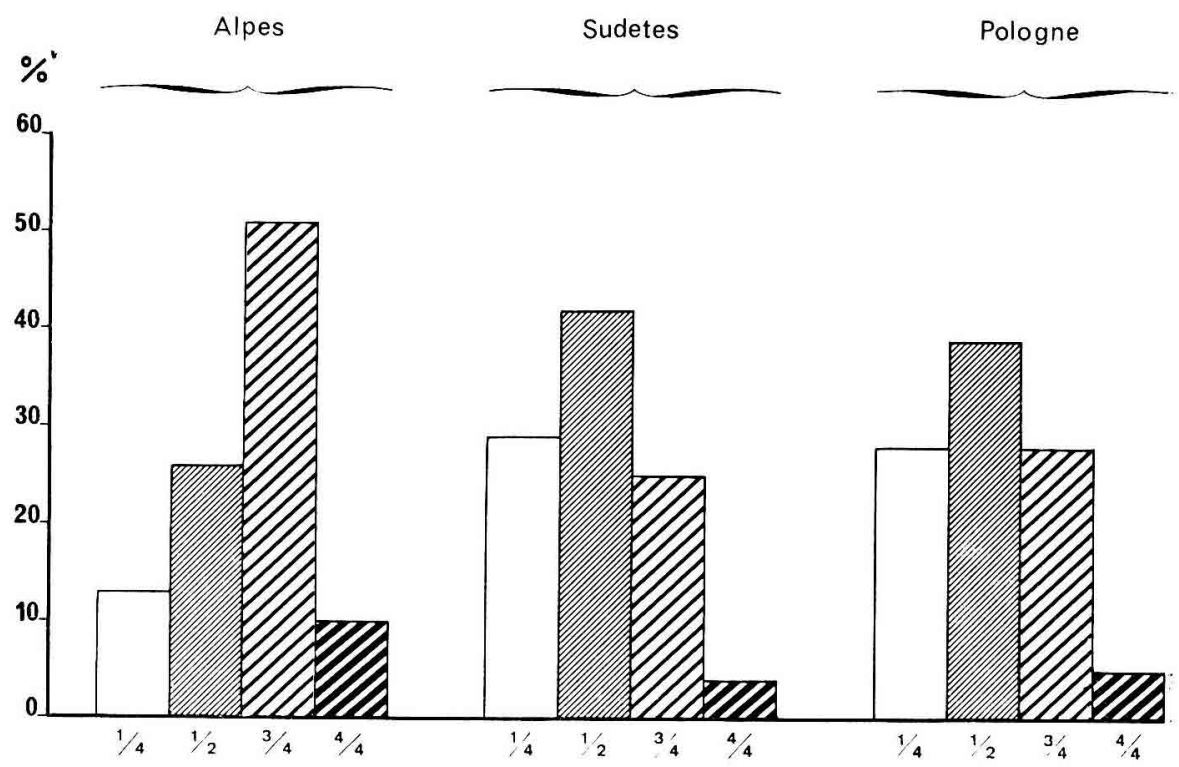

FIG. 6

Extension latérale des infections chez trois provenances de Larix decidua, quatre ans après l'inoculation.

Lateral extension of infection in $\mathrm{L}$. decidua from three provenances, 4 years after inoculation.

\subsection{Caractéristiques des infections réussies}

Il ne nous a pas été possible dans le cas présent de prendre en compte les: mortalités provoquées par les infections car une transplantation en cours d'essai a. entraîné de nombreuses mortalités anormales. 
La figure 7 montre que parmi les inoculations considérées comme réussies, après huit mois seule la provenance Pologne se révèle différente : aucun chancre complet ne s'est développé et très fréquents sont les cas où l'affaissement d'écorce n'est accompagné d'aucun autre symptôme. Le singularisme de cette provenance persiste au bout de quatre ans : les chancres complets demeurent nettement moins fréquents que chez les autres provenances.
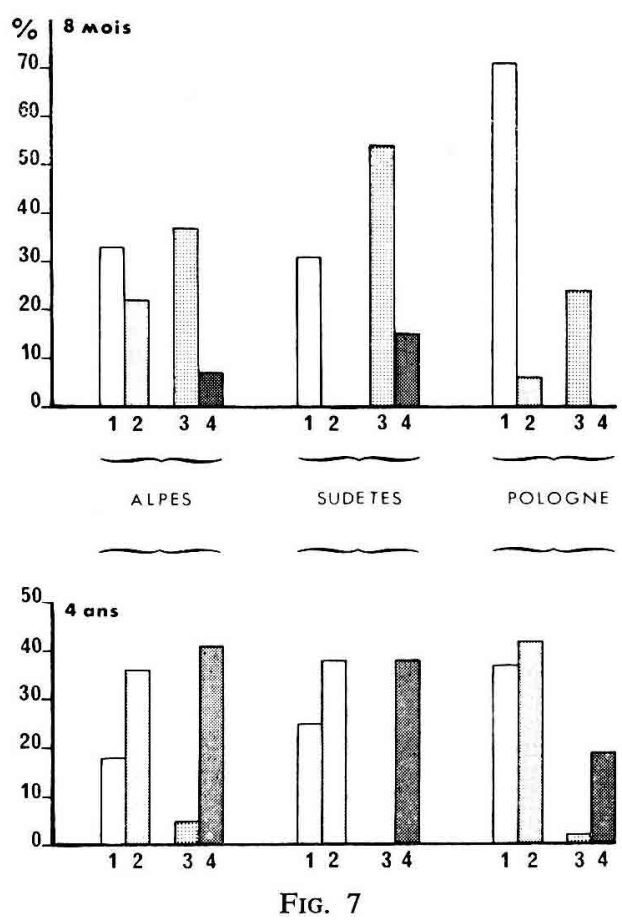

Caractéristiques des infections réussies chez trois provenances de Larix decidua, les symboles $(1,2,3,4)$ ont la même signification que dans la figure 4.

Characteristics of the successfull infections in three provenances of L. decidua. Symbols 1, 2, 3, 4 idem as figure 4.

\section{Discussion}

Les premières inoculations de L. willkommii sur mélèze sont dues à HaRTIG (1880) qui reproduisit la maladie en appliquant des fragments de chancres sur des blessures artificielles de rameaux et de troncs. Ultérieurement divers auteurs réussirent également des infections par blessure en utilisant un inoculum mycélien de culture pure (HiLEY, 1919 ; Plassman, 1927 ; Hahn \& Ayers, 1938 ; Manners, 1957 ; Day, 1958 ; Ito et al., 1963 ; BUCZAKI, 1973). HAHN \& AYERs (1938) montrèrent que l'inoculation de tissus âgés aboutit à des échecs, ainsi que celles pratiquées sans blessure. La comparaison des résultats de ces auteurs est rendue difficile par la variété des blessures 
réalisées : fentes de 1 à $2 \mathrm{~cm}$, enlèvement de plages d'écorce de diverses formes ou dimensions, parfois adjonction d'une congélation artificielle, ou d'une brûlure.

Nos résultats montrent en effet que l'appréciation de l'infection peut varier selon les dimensions des blessures pratiquées, notamment à cause des exsudations de résine qui peuvent être abondantes et se poursuivre jusqu'au moment de la cicatrisation complète en dehors de toute intervention parasitaire; il est dès lors primordial de pratiquer de nombreuses blessures témoins pour apprécier la durée de cette exsudation de résine de blessure. La standardisation des blessures présente donc une importance particulière. Il en va probablement de même pour l'inoculum, bien que les deux types d'apport que nous ayons réalisés (support gélosé, support grain d'avoine) ne nous permettent pas d'étayer cette affirmation.

Les expérimentateurs antérieurs employèrent des souches aux caractéristiques variées; ainsi HAHN \& AYERS utilisèrent indifféremment des souches monoascosporées ou des apothécies, Ito et al. puis ManNers des cultures monoascosporées conservées sur milieu gélosé depuis 1 à 3 ans. Quant à nous, toujours dans un but de standardisation, nous nous sommes attachés à n'utiliser qu'une même souche (issue d'un chancre actif) au cours de nos divers essais, en prenant soin de lui conserver a priori son caractère pathogène en la réisolant de matériel vivant infecté artificiellement.

Les résultats obtenus par les auteurs antérieurs montrent que la saison d'inoculation n'est pas sans influence sur le taux d'infection obtenu. Ainsi, Iто et al. au Japon enregistrent un échec complet des inoculations faites en période de végétation (juin) sur $L$. decidua et $L$. leptolepis, et des succès en repos végétatif (décembre); des réussites en période de végétation sont cependant signalées : 12,7 p. 100 (Buсzacki pour $L$. decidua et $L$. leptolepis confondus), 25-35 p. 100 (HAHN \& Ayers sur L. decidua) quoique toujours inférieures à celles obtenues en repos végétatif (67 p. 100 BuCZACKI, 50-63 p. 100 HAHN \& AYERs). Les résultats que nous avons obtenus vont en général dans le même sens : les inoculations réalisées en février et septembre aboutissent en définitive à des taux de réussite supérieurs à ceux des inoculations de mai et juin. La faible réussite des inoculations réalisées en décembre peut sembler contradictoire mais. la survie du pathogène pourrait avoir été particulièrement affectée par la longue période de basses températures qui a suivi l'inoculation.

Il apparaît en définitive que l'implantation du pathogène (trois premiers mois) semble peu dépendante de la saison, mais qu'il n'en va pas de même pour son implantation ultérieure qui semble plutôt se produire en période de repos végétatif ou en tout début de saison de végétation, à condition bien entendu que le pathogène ait pu se maintenir vivant (saprophyte ou infection latente ?) au niveau du site inoculé, ce qui n'est probablement possible que pendant une durée limitée.

L'ensemble de ces résultats laisse donc penser que l'implantation du pathogène est conditionnée par l'état physiologique de l'hôte (activité ou repos végétatif) peut-être au moment de l'inoculation mais surtout par son évolution dans les mois qui suivent.

La méthode d'inoculation que nous avons adoptée ayant été le plus possible standardisée, nous admettrons que les variations de comportement observées proviennent pour la plus grande partie de l'hôte lui-même. Dans nos essais, ces variations de l'hôte ne sont pas toutes d'origine génétique, en effet, bien que les plants étudiés aient été cultivés en conditions homogènes (pépinière), une source de variation dont l'importance reste à déterminer est l'hétérogénéité physiologique des organes inoculés; les. 
rameaux latéraux ainsi que les tiges des plants greffés sont loin de tous présenter des vigueurs comparables. Le nombre de répétitions doit permettre de pallier cet inconvénient.

Nous avons vu que ni les 3 espèces de mélèze testées, ni les provenances de $L$. decidua ne peuvent être clairement distinguées entre elles d'après le taux final de réussite des inoculations. Les inoculations de HAHN \& AYERs permettent une constatation comparable pour $L$. decidua et $L$. leptolepis. Les taux d'infection élevés qui ont été obtenus sont sans rapport avec ce qui est observé en conditions naturelles, mais les deux situations n'ont rien de comparable, les blessures notamment éliminent a priori les phénomènes de résistance qui peuvent intervenir dès le début des infections naturelles.

La rapidité d'implantation du pathogène, jugée d’après les taux d'infection dans les trois premiers mois, permet une distinction intéressante au niveau des espèces, qui conduirait au classement suivant par sensibilité décroissante : d'une part $L$. decidua et d'autre part $L$. leptolepis et $L$. eurolepis. Ceci est compatible avec ce qui est observé en nature. (La même observation ne peut malheureusement pas être faite pour les provenances de $L$. decidua à cause des différences de mode opératoire). Ce phénomène pourrait être lié à l'existence de facteurs de résistance préformés ou rapidement induits.

Lorsque le pathogène est bien implanté dans les tissus, après un an ou plus, un véritable phénomène chancreux se développe et on peut considérer alors que les relations hôte-pathogène sont tout à fait comparables à celles des conditions naturelles, quelle qu'ait été la voic de pénétration. L'analyse de ce phénomène chancreux a été faite en considérant essentiellement deux critères : l'exsudation active de résine et l'extension latérale des chancres; les fructifications n'ayant été prises en compte que comme indicatrices de la présence du pathogène. L'exsudation de résine est en effet très caractéristique du processus chancreux engenciré par $L$. willkommii sur mélèze, comme cela se vérific très aisément en conditions naturelles.

Quant à l'cxtension latérale, si elle n’est pas totalement indépendante de la vitesse initiale d'implantation du pathogène liée à la procédure artificielle d'inoculation elle demcure sous la dépendance des capacités de réaction de l'hôte.

Selon ces critères, il apparaît certaines différences entre les espèces étudiées. Les infections sur $L$. decidua conduisent à des perturbations chancreuses graves (classes 3 , 4,5 ; figure 4) accompagnées d'une importante extension latérale (moyenne 70 p. 100, $\$ 2.221)$; L. curolepis présente un comportement semblable mais l'extension latérale tendrait à plafonner plus rapidement (moyenne 65 p. 100, \$ 2.221); L. leptolepis présente un comportement bien différent : si l'extension latérale est importante (moyenne 74 p. $100, \$ 2.221$ ), elle est surtout le fait des cas d'évolution chancreuses typiques (classes 3, 4, 5; fig. 4) qui sont nettement moins fréquentes chez les deux espèces précédentes.

Des différences apparaissent également entre les provenances de L. decidua: c'est la provenance alpine qui présente (au bout de quatre ans) les perturbations chancreuses les plus prononcées (classes 3 et 4 , fig. 7) associées aux extensions latérales les plus importantes $(\$ 2.321)$. Les provenances qui se révèlent dans nos essais les plus favorables au développement du pathogène sont donc celles qui sont réputées les plus scnsibles en nature (provenances alpines). 
Ainsi il apparaît que la méthode des inoculations sur blessure permet une certaine appréciation de la sensibilité à condition de combiner plusieurs critères : rapidité d'établissement des infections, extension et caractéristiques des chancres comme cela est résumé ci-après.

\begin{tabular}{|c|c|c|c|c|}
\hline & $\begin{array}{c}\text { Rapidité } \\
\text { implantation } \\
\text { initiale } \\
\text { (3 à } 6 \text { mois) }\end{array}$ & $\begin{array}{c}\begin{array}{c}\text { Perturbations } \\
\text { chancreuses } \\
\text { graves } \\
\text { (classes } 3,4,5)\end{array}\end{array}$ & $\begin{array}{c}\text { Extension } \\
\text { latérale }\end{array}$ & $\begin{array}{c}\text { Taux } \\
\text { infection } \\
\text { définitif }\end{array}$ \\
\hline $\begin{array}{l}\text { Larix decidua } \\
\text { Larix eurolepis } \\
\text { Larix leptolepis } \\
\end{array}$ & $\begin{array}{r}++ \\
++ \\
++ \\
\end{array}$ & $\begin{array}{r}+++ \\
+++ \\
+ \\
\end{array}$ & $\begin{array}{r}++ \\
++ \\
+++ \\
\end{array}$ & $\begin{array}{l}+++ \\
+++ \\
+++\end{array}$ \\
\hline $\begin{array}{l}\text { Larix decidua } \\
\text { Alpes } \\
\text { Sudètes } \\
\text { Pologne }\end{array}$ & - & $\begin{array}{r}++ \\
+ \\
+ \\
+\end{array}$ & $\begin{array}{r}+ \\
+ \\
+\end{array}$ & $\begin{array}{l}+++ \\
+++ \\
+++\end{array}$ \\
\hline
\end{tabular}

\section{Conclusion}

Bien qu'éliminant d'emblée les premières séquences de l'infection naturelle au cours desquelles des phénomènes de résistance décisifs peuvent se développer, les inoculations artificielles sur blessure permettent la mise en évidence de différences entre espèces et provenances de mélèze qui coïncident avec les différences de sensibilité communément constatées en conditions naturelles. Les différences ne s'expriment pas en terme de taux final d'infection, mais peuvent être appréciées par l'évolution du taux d'infection au cours des trois mois qui suivent l'inoculation. Elles peuvent être également appréciées ultérieurement en analysant selon deux critères les infections développées : leur extension diamétrale et les exsudations actives de résine pour lesquelles la meilleure période d'observation est le printemps (mai-juin). A condition de procéder de façon très standardisée, en ce qui concerne l'inoculum, les blessures et les organes auxquels on s'adresse, il apparaît donc possible d'apprécier par l'inoculation de blessures artificielles, les différences de sensibilité au $L$. willkommii à l'intérieur du genre Larix, au niveau des espèces et aussi des provenances. Une méthodologie plus fine devrait cependant être recherchée qui tiendrait compte des réserves faites en matière de pression d'inoculum; des inoculations réalisées sur blessures par apport de spores et non plus de mycélium pourraient permettre d'atteindre cet objectif, en outre la variabilité du pathogène pourrait ainsi être considérée. Une méthode qui prendrait en compte les toutes premières séquences de résistance serait certainement la plus intéressante; sa mise au point suppose une bonne connaissance du mode d'infection du L. willkommii, mais dans ce domaine les données sont très fragmentaires et de nombreux travaux restent à faire. 


\section{Remerciements}

Nous tenons à exprimer nos remerciements à la Station d'Amélioration des Arbres Forestiers d'Orléans et à l'équipe de la pépinière du C.N.R.F. pour le matériel fourni. Que Mesdames Arlette SCHIPFER et Micheline ROzOT soient remerciées pour leur collaboration dans la réalisation des inoculations, Monsieur J.-L. Renoux pour celle des graphiques et les chercheurs du Laboratoire de Pathologie forestière pour les discussions que nous avons enes avec eux.

\section{Summary \\ Feasibility of evaluating the susceptibility of Larix to Lachnellula wilkommii by artificial inoculation}

The authors try to determine whether known differences in host susceptibility can be correctly assessed by artificial inoculation. The aim is to establish a suitable methodology. Three species $L$. decidua from 3 provenances : French Alps, Czecho-Slovak Sudeten, Central Poland; L. eurolepis, L. leptolepis. The pathogen in the form of mycelium was applied to artificial wounds. The infections were assessed according to the following criteria : sinking of the bark (present/absent, lateral spread) fruiting of the fungus, pathological resinous exudate, death of inoculated parts.

The final level of infection does not generally differ between the hosts species unless the inoculations were performed during December. However, interesting differences appeared when the following criteria were considered jointly : 1) rapidity of pathogen development during the first six months, 2) the frequency of serious cankerous development (sinking of the bark together with pathological resinous exudate), 3) spread of the sunken bark symptom.

Subsequent ranking of the host species show some differences. $L$. decidua was more susceptible than the others and in $L$. decidua material from the Alps was more susceptible than that from Eastern Europe. These results indicate a possible value of artificial inoculations but the methods will require further rafinement to separate the different host species.

\section{Références bibliographiques}

Bouvarel P., 1957. Appel pour la sélection des mélèzes d'élite. Rev. for., 599-600.

BUCZACKI S.T., 1973. Some factors governing mycelial establishment and lesion extension in the Larch canker disease. Eur. J. for. Pathol., Band 3 (1), 39-49.

BUCZACKI S.T., 1973. Observations on the infection biology of Larch canker. Eur. J. for. Pathol., Band 3 (4), 228-232.

DAY W.R., 1958. The distribution of mycelia in European larch bark, in relation to the development of canker. Forestry, 31, 63-86.

DAY W.R., 1962. The development of canker on European larch, Larix decidua Mill. Phytopathology, 44 (4), 313-323.

EdLin H.L., Nimmo M., 1956. Tree injuries. Their causes and prevention. Thames and Hudson London, New York, 124-126.

Fourchy P., 1952. Etudes sur l'écologie et la sylviculture du mélèze (Larix europea D.C.). Ecologie du mélèze particulièrement dans les Alpes françaises. Extrait des Annales de l'Ecole nationale des Eaux et Forêts de la Station de Recherches et Expériences, 13, $1-137$.

Fourchy P., 1957. Toujours le mélèze. Rev. for. fr,. décembre (12), 898-900. 
Gathy P., 1959. A propos du mélèze d'Europe en Belgique. Détermination de l'origine des peuplements par l'analyse morphologique des cônes. Bull. Soc. R. for. Belg. (8-9), 398-413.

HAHN G.G., Axers T., 1938. Failure of Dasyscypha willkommii and related large-spore species to parasitize Douglas fir. Phytopathology, 28, 50-57.

HAHN G.G., Ayers T., 1943. Role of Dasyscypha willkommii and related fungi in the production of canker and dieback of Larches. J. for., 483-495.

Haktig R., 1880. Die Lärchenkrankheiten, insbesondere der Lärchenkrebspilz, Peziza willkommii R. Hartig. Untersuch. forstb. Inst. München 1, 63-87.

Hartig R., 1891. Traité des maladies des arbres. Paris, Nancy : Berger-Levrault et $\mathrm{C}^{1 e}, 311$.

HAYES A.J., 1975. The mode of infection of lodgepole pine by Crumenula sororia Karst and the susceptibility of different provenances to attack. Forestry, 48 (1), 99-113.

HileY W.E., 1919. The Fungal diseases of common larch. Oxford, Clarendon Press.

Iто K. et al., 1963. Larch canker in Japan. Bull. Gov. For. Exp. Stn, 155, Tokyo, Japan, July, 23-47.

Leibundeut H. et al., 1964. Etudes sur diverses provenances de mélèze européen (Larix decidua L.) et la variabilité de leur infection par le chancre du mélèze (Dasyscypha willkommii Hart.). J. for. suisse, 4, avril, 255-260.

Kurkela T., 1970. Lachnellula willkommii, lehtikuusensyövän aiheuttaja ja Lachnellula occidentalis lehtikuusella suomessa. Karstenia, 11, 41-45.

ManNers J.G., 1953. Studies on larch canker : the taxonomy and biology of Trichoscyphella willkommi (Hart.). Nannf. and related species. Trans. Br. mycol. Soc., 36, 362-374.

Manners J.G., 1957. Studies on larch cander : the incidence and anatomy of cankers produced experimentaly either by inoculation or by freezing. Trans. Br. mycol. Soc., 40 (4), 500-508.

МсСомв A.L., 1955. The European Iarch : its races, site requirements and characteristics. For. Sci. (1), 298-318.

Pardé J., 1957. Plaidoyer pour le mélèze. Rev. for. fr., août-septembre, 634-651.

PAwSEY R.G., Young W.T., 1969. A reappraisal of canker and dieback of European Larch. Forestry, 42 (2), 145-164.

Plassmann E., 1927. Untersuchungen über den Lärchenkebs. Verlag von J. Neumann-Neudamm, 1-88.

Pourtet J., 1953. Le Mélèze au Japon. Rev. for. fr., avril, 291-296.

SCHOBER R., 1977. Vomm II. Internationalen Lärchenprovenienzversuch. Ein Beitrag zur Lärchenherkunftsfrage. Schriftenreihe der forstlichen Fakultät der Universität Göttingen, 49, 359 . 